\title{
Migraine Prophylaxis: Which Drugs Work and Which Ones Don't
}

\author{
Hans-Christoph Diener, MD \\ Department of Neurology, University Hospital Essen, Essen, Germany.
}

$J$ Gen Intern Med 28(9):1125-6

DOI: $10.1007 / \mathrm{s} 11606-013-2469-2$

(c) Society of General Internal Medicine 2013

$\mathrm{T}$ he paper by Shamliyan et al. ${ }^{1}$ in this issue of JGIM is a very important contribution to headache research. The authors conducted a systematic literature review of drug treatment for the prevention of episodic migraine. They analysed randomised controlled trials (RCTs) and performed meta-analyses where appropriate. The two important outcomes examined in the analysis are $\mathrm{a} \geq 50 \%$ reduction in migraine frequency and adverse events leading to treatment discontinuation.

What are the strengths of this paper?

The authors are experts in this kind of analysis. The methods are complicated but appropriate. The authors have no connection with industry and therefore are not subject to bias. They report the outcomes of their analyses and refrain from treatment recommendations.

\section{What are the weaknesses?}

First, the authors restrict their analysis to drugs approved in the US, rather than taking a more global view. Flunarizine, which is used in most countries outside of the US for migraine prevention, was not analysed. In addition, beta-blockers other than propranolol and timolol that are approved for migraine prevention in most European countries (for example metoprolol and bisoprolol) were also not included. Conversely, the authors included divalproex, which is not approved for migraine prevention in most European countries, because authorities consider the teratogenic risk to be higher than the potential benefit in migraine prevention.

Second, the paper illustrates problems inherent to metaanalyses. For example, this meta-analysis suggests an apparent benefit of treatment when several underpowered small studies are pooled. In some cases, the power of meta-analyses to uncover such benefits is helpful. An example is the placebocontrolled studies performed for the secondary prevention of stroke with aspirin. Eight consecutive underpowered studies failed to show a significant difference in the primary endpoint, and only a meta-analysis demonstrated the efficacy of aspirin. ${ }^{2}$ A negative example can be found in this paper. Nimodipine was

Published online May 1, 2013 investigated in two properly powered and conducted studies and found not to be effective compared to placebo., ${ }^{3,4}$ Adding data from poorly controlled and underpowered studies in a meta-analysis, as in this paper, gives the wrong impression that nimodipine is as effective in migraine prevention as propranolol. Another example illustrated in this meta-analysis involves gabapentin. Most of the published trials are poorly conducted, underpowered, or have manipulated statistical analyses, such as modified intention-to-treat analyses. ${ }^{5}$ The meta-analysis in this paper indicated possible efficacy. Yet, in the time between the submission and publication of this paper, a recent well-powered dose finding trial was published investigating four doses of gabapentin as compared with placebo for migraine prevention. This trial showed no benefit for gabapentin. ${ }^{6}$

Another problem inherent in meta-analyses that this paper illustrates is the potential for publication bias. We can assume that in the past a number of negative trials on migraine prevention conducted by pharmaceutical companies were not published. With the need to register controlled trials prospectively, there may be less risk of such biases in the future.

\section{Why is this paper important?}

This paper clearly demonstrates how poorly the majority of trials that investigated drugs for migraine prevention (including a number of studies in which the author of this editorial was the principal investigator) were done. Most trials were done without a proper phase II dose-finding trial, were underpowered, and had major flaws in trial design and inadequate statistical analyses. This only improved slowly in the last decade when the International Headache Society published guidelines on how to plan and execute clinical trials for migraine prevention. ${ }^{7}$

Another important aspect of this paper is its potential role in informing the writing of treatment guidelines. In the past, a group of headache specialists would sit around a table, claiming to have knowledge of the published literature, and write and publish (mostly eminence-based) treatment guidelines for the prevention of migraines. With the introduction of reasonable methodological standards for how to perform systematic reviews and develop guidelines (for example, the GRADE system), ${ }^{8-10}$ the part of the process focusing on the systematic review of the literature has now been handed over to specialists in evidence-based medicine, epidemiology, and biostatistics who are competent and unbiased (as in this paper). The results of these analyses are then put into clinical context 
by headache clinicians and trialists in order to create and publish evidence-based treatment guidelines. Ultimately, clinicians who see patients in everyday practice can get a good impression of which drugs really work and which adverse events have the highest impact on adherence and compliance. Such robust guideline development methodologies also have the benefit of integrating as much expertise as possible in the translation of a review into a guideline by including pharmacologists, epidemiologists, specialists from regulatory bodies (particularly for serious adverse events), and, depending on the frequency and severity of adverse events, specialists from other fields (for example, cardiologists for adverse events related to beta-blockers). In the field of migraine prevention, we have also found it helpful to integrate patient organisations into this process.

I look forward to this important paper informing the next generation of guidelines on the prevention of frequent episodic migraine through pharmacotherapy.

Corresponding Author: Hans-Christoph Diener, MD; Department of Neurology, University Hospital Essen, Hufelandstrasse 55, Essen, 45147, Germany (e-mail: h.diener@uni-essen.de).

\section{REFERENCES}

1. Shamliyan T, Choi J-Y, Ramakrishnan R, Biggs Miller J, et al. Preventive pharmacologic treatments for epsiodic migraine in adults. J of Gen Intern Med. 2013 doi:10.1007/s11606-013-2433-1.

2. Algra A, van Gijn J. Cumulative meta-analysis of aspirin efficacy after cerebral ischaemia of arterial origin. J Neurol Neurosurg Psychiatry. 1999;65:255.

3. Migraine Nimodipine European Study Group (MINES). European multicenter trial of nimodipine in the prophylaxis of common migraine (migraine without aura). Headache. 1989;29:633-638.

4. The Migraine Nimodipine European Study Group (MINES). European multicenter trial of nimodipine in the prophylaxis of classic migraine (migraine with aura). Headache. 1989;29:639-642.

5. Mathew NT, Rapoport A, Saper J, Magnus L, Klapper J, Ramadan N, et al. Efficacy of gabapentin in migraine prophylaxis. Headache. 2001;41:119-128.

6. Silberstein S, Goode-Sellers S, Twomey C, Saiers J, Ascher J. Randomized, double-blind, placebo-controlled, phase II trial of gabapentin enacarbil for migraine prophylaxis. Cephalalgia. 2013;33(2):101-111. Epub 2012/11/21.

7. Tfelt-Hansen P, Block G, Dahlof C, Diener H-C, Ferrari MD, Goadsby PJ, et al. Guidelines for controlled trials of drugs in migraine: second edition. Cephalalgia. 2000;20:765-786.

8. Guyatt GH, Oxman AD, Kunz R, Falck-Ytter Y, Vist GE, Liberati A, et al. Going from evidence to recommendations. BMJ. 2008;336(7652):10491051. Epub 2008/05/10.

9. Guyatt GH, Oxman AD, Kunz R, Vist GE, Falck-Ytter Y, Schunemann HJ, et al. What is "quality of evidence" and why is it important to clinicians? BMJ. 2008;336(7651):995-998. Epub 2008/05/06.

10. Guyatt GH, Oxman AD, Vist GE, Kunz R, Falck-Ytter Y, AlonsoCoello P, et al. GRADE: an emerging consensus on rating quality of evidence and strength of recommendations. BMJ. 2008;336(7650):924926. Epub 2008/04/26. 